\title{
A atipicidade estrutural do uso do "não" após a reforma ortográfica
}

The atypical structure of the use of "not" after the orthographic reform

Thiago Soares de Oliveira, Escola de Administração Judiciária, so.thiago@hotmail.com

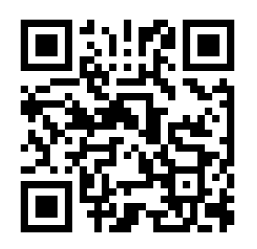

C om a publicação do Decreto $n^{\circ} 6.583$, de 29 de setembro de 2008, que promulgou o Acordo Ortográfico da Língua Portuguesa de 1990, assinado pelos países lusófonos, validaram-se algumas alterações e inclusões ortográficas na tentativa de se simplificar a escrita entre eles, pondo fim à existência de divergentes normas ortográficas oficiais no idioma, unificando-as sem que houvesse, entretanto, uma remodelagem fonética.

Dadas as peculiaridades das diversas nações lusófonas, algumas normas foram agasalhadas sem obstáculos quanto à aceitação, como a queda da acentuação nos hiatos "oo" e "ee", compostos por vogais dobradas; outras, todavia, por serem estranhas ao Português brasileiro, não foram recepcionadas entusiasticamente, óbice não preocupante visto que o Decreto 6.583/08 prevê um período de transição que se estende até 31 de dezembro de 2015, data-limite para a coexistência entre a norma ortográfica em vigor e a implementada pelo Acordo de 1990.

Entre as inovações trazidas pela convenção está a queda do hífen nos nomes compostos precedidos pelo vocábulo "não".
A ausência de tal marcação gráfica gera, contudo, dúvidas acerca da classificação morfológica do vocábulo que, embora consagrado como advérbio, transpõe-se a prefixo adequandose à formação do substantivo composto. Além disso, emerge também a questão semântica pontuada pelo sentido negativo enraizado ao próprio vocábulo, visto que, a ausência do traço de união supostamente inibe a noção de composição que sobrevém ao substantivo composto.

Sem a intenção de esgotar o assunto, este trabalho propõe, em suma, uma análise teórica com supedâneo normativo, a fim de entender como a reforma ortográfica a que o Brasil manifestou adesão levou à gênese de uma atipicidade estrutural relativamente ao uso do vocábulo "não" em função de prefixo com valor negativo. Para tanto, este conciso artigo tomará como ponto de partida a observação do termo em comento sob a ótica da classificação morfológica, seguindo pela análise do valor semântico de outros prefixos de valor negativo, findando na proposta de um enfoque a respeito da atipicidade que abate a nova estrutura de uso do prefixo "não". 


\section{BREVES CONSIDERAÇÕES A RESPEITO DA ABORDAGEM ADOTADA}

Por não serem afeitos aos estudos da linguagem ou por mero desconhecimento, não raro surgem os que afirmam que a gramática não está contida no campo de estudo da Linguística. Essa concepção inadequada leva à conclusão um tanto pejorativa de alguns linguistas de que a gramática tradicional articula-se em "um exame não científico do fenômeno gramatical" (WEEDWOOD, 2002, p.10), esquecendo-se de que muitas das noções aproveitadas pelas abordagens modernas podem ser encontradas naquelas obras muito antigas.

Apesar disso, já que se trata de uma área de conhecimento abrangente, "a linguística, tal como hoje é compreendida, inclui todos os tipos de exame dos fenômenos da linguagem, inclusive os estudos gramaticais tradicionais e a filologia" (idem, p. 10).

A partir desse viés explanativo introdutório, desarrazoado seria afirmar que uma abordagem formalista dos fenômenos da linguagem é contraproducente a ponto de afastá-la do tom científico que se exige em um trabalho analítico cuja pretensão precípua recai sobre a atipicidade estrutural de determinado elemento da língua, ainda que, para tanto, sejam resgatados conceitos normativos que se adequem ao propósito da pesquisa. De forma análoga, não seria prudente alegar que a adoção de tais conceitos com fim específico ao tom que sugere a linguística da forma é, na verdade, desconhecer superficial ou profundamente os conceitos linguísticos, uma vez que ao pesquisador pertence a faculdade de decidir acerca da melhor forma de se abordar um conteúdo, não significando, portanto, o desconhecimento de outras concepções que tangem à língua, mas a opção por determinado modo de dar enfoque ao objeto de estudo proposto.

Tecendo explicações acerca da linguística do sistema, aqui considerada linguística da forma, cuja paternidade é atribuída a Ferdinand de Saussure, Koch $(2012$, p. 8) explica que, "em termos linguísticos, isto significa descrever, num determinado estádio da língua (isto é, sincronicamente), as unidades pertencentes aos diversos níveis da língua (fonemas, morfemas, etc.), sua posição no sistema e suas regras combinatórias". A esta noção, a autora opõe a definição de "linguística do discurso, isto é, uma linguística que se ocupa das manifestações linguísticas produzidas por indivíduos concretos em situações concretas, sob determinadas condições de produção" (idem, p. 9), deixando claro que, apesar de pertencerem ao "estudo científico da língua(gem)" (WEEDWOOD, 2002, p. 9), uma e outra vertentes adotam meios distintos de se debruçar sob os aspectos de seu objeto de pesquisa. Por isso, não se pretende afirmar que existem duas linguísticas, mas pelo menos duas formas de se perceber a linguagem.
Nessa direção, entende-se que a abordagem escolhida para a observação do comportamento estrutural do "não" após a Reforma Ortográfica de 1990 é adequada, na medida em que compila o conhecimento produzido tanto por autores adeptos da Linguística do Sistema quanto por aqueles que compartilham dos pressupostos que norteiam a Linguística do Discurso. Todavia, uma vez que este trabalho pretende uma análise primordialmente estrutural e secundariamente semântica, é natural que aqueles estudiosos sejam mencionados com maior ênfase do que estes.

Não obstante as considerações anteriormente tecidas, é preciso ressaltar que, embora predominantemente formalista, a abordagem adotada como meio de análise não pretende desconstruir os pressupostos que sustentam a Linguística do Discurso, dados o caráter social das línguas que, na verdade, "não existem sem as pessoas que as falam" (CALVET, 2002, p. 12) e a importância do entendimento de que, com efeito, a língua "é intrinsecamente heterogênea, múltipla, variável, instável e está sempre em desconstrução e em reconstrução" (BAGNO, 2007a, p. 36).

Como não é propósito tratar enfaticamente da questão da variação linguística da forma como o faz a Linguística do Discurso e a Sociolinguística, apenas as considerações pontuais a respeito desse assunto serão citadas no corpo do trabaIho, sendo certo, contudo, que as abordagens propostas por estudiosos, como Bagno (2007b), Bortoni-Ricardo (2004), Perini (1985), Possenti (1996), Scherre (2005) e Takazaki (2004) são de grande valia para aqueles que pretendem se aprofundar no estudo da variação linguística e entender o estreito vínculo da língua "com a dinâmica social e com os usos que dela fazem os seus falantes" (BAGNO, 2007a, p. 73).

Vale ressaltar ainda que, neste artigo, coexistem dois entendimentos: o primeiro de que a gramática tem a sua importância como padronizadora de um sistema linguístico que, da mesma forma que um sistema social, precisa ser normatizado, não com o intuito de segregar, promover o preconceito e fornecer " 0 acesso aos lugares de poder no qual ela é empregada" (HANKS, 2008, p. 49), mas de preservar a existência de um padrão que ainda é necessário aos trabalhos que exigem rigor gramatical, como forma de abordagem de fenômenos linguísticos que dela dependam; e o segundo, que comunga com a noção de que, quando se trata de gramática da Língua Portuguesa, o que ocorre é que, quase sempre, "tudo se reduz a um exercício mecânico de pôr no papel não importa o quê; [...] a preocupação com a revisão do que foi escrito se limita a corrigir pontos de sua superfície linguística, como ortografia, concordância verbal, crases e outras questões gramaticais" (ANTUNES, 2005, p. 26).

Assim sendo, fica o registro final de que, ainda que se caminhe para o consenso de que a gramática não dá conta da 
explicação nem dos fenômenos que suplantem a análise estrutural nem dos que secundariamente a subsidiam, por não ser possivel uma análise desvinculada (como é o caso da proposta deste trabalho, que não se furta em abordar o aspecto estrutural em coordenação com o semântico), ela preservará a sua importância não só por ser um instrumento representativo de um processo histórico, mas também porque sempre servirá de suporte para a elaboração de trabalhos acadêmicos e outros em que o rigor seja exigência.

\section{A QUESTÃO DA CLASSIFICAÇÃO MORFOLÓGICA}

Tradicionalmente, a palavra "não" é classificada como advérbio, isto é, "expressão modificadora que por si só denota uma circunstância (de lugar, de tempo, modo, intensidade, condição, etc.) e desempenha na oração a função de adjunto adverbial" (BECHARA, 2009, p. 287), sendo, "fundamentalmente, um modificador do verbo" (CUNHA e CINTRA, 2012, p. 555). Com efeito, essa função básica é ratificada por Cegalla (2000, p. 243) ao afirmar que "a maioria dos advérbios modificam 0 verbo, ao qual acrescentam uma circunstância. Só os de intensidade é que podem também modificar adjetivos e advérbios".

Em complementação à asserção de Cegalla (2000), vale ressaltar que Cipro Neto e Infante (1998) asseveram que não só os advérbios de intensidade mas também os de modo podem modificar adjetivos e advérbios, já que, "diferentemente do que seu nome indica, 0 advérbio não é modificador exclusivo do verbo" (Idem, p. 270), caracterizando não apenas o processo verbal, mas também as circunstâncias nas quais esse processo se desenvolve.

Essa tradição classificatória em que a palavra "não" é registrada como advérbio encontra respaldo nas obras de famosos dicionaristas, tais como Aurélio Buarque de Holanda Ferreira (ABHF) e Celso Pedro Luft (CPL). A fim de corroborar essa assertiva, vale consultar o Dicionário Prático da Língua Portuguesa de ABHF (1997), no qual consta: "Não, adv. 1. Exprime negação [Pode ser partícula de realce: 0 que eu não faria por você!]. sm. 2. Negativa; recusa."

Analogamente à obra anteriormente citada, no Superdicionário da Língua Portuguesa, assinado por CPL (2000), o verbete é assim definido: "Não, adv. Expressão de negação; antônimo de sim; de modo nenhum; partícula expletiva ou de realce: imagine o que não irão pensar de mim!; s. m. negativa; recusa (Do lat. Non.)".

Considerando ainda que o advérbio "não" é classificado como de negação por autores como Nicola e Infante (1997), Cunha e Cintra (2012), Bechara (2009) e Cegalla (2000), não se confundindo com os advérbios de intensidade tampouco com os de modo, capazes de modificar tanto verbos como adjetivos e outros advérbios, é possível perceber que, adstrito a modificador de verbo, o advérbio "não", quando se relaciona àquelas categorias gramaticais, o faz de forma inicialmente atípica. Isso significa que, essencialmente, os advérbios de negação são modificadores de verbos.

Dessa forma, articulado em orações como $O$ menino não comeu o bolo e $O$ aluno não estava doente, a palavra não classifica-se como advérbio de negação, ou seja, "é palavra invariável que modifica essencialmente o verbo, exprimindo uma circunstância" (SACCONI, 2001, p. 296), nesses casos, a circunstância de negação.

Para fins deste trabalho, entende-se o vocábulo "não" como prefixo, isto é, um elemento mórfico que, anteposto a uma base lexical, empresta ao radical uma nova significação (BECHARA, 2006), e não como radical, conceituado como "o elemento básico e significativo das palavras, consideradas sob 0 aspecto gramatical e prático, dentro da língua portuguesa atual" (CEGALLA, 2000, p. 91), visto que se pretende, teoricamente, uma análise da atipicidade estrutural do mencionado vocábulo advinda da queda do hífen após a Reforma Ortográfica. Logo, adota-se o entendimento de Cunha e Cintra (2012), considerando que

[...] os prefixos formam novas palavras que conservam de regra uma relação de sentido com o radical derivante; processo distinto da composição, que forma palavras não raro dissociadas pelo sentido dos radicais componentes (Idem, p. 98).

Apesar de este breve artigo não intencionar a explanação sobre os processos de formação de palavras aos quais pode estar relacionado o vocábulo "não", cumpre registrar, em caráter sucinto e meramente explicativo, que "o que diferencia a composição da prefixação é o fato de a primeira apresentar a união de elementos radicais, e de a segunda estruturar-se a partir de um afixo mais um radical" (PEREIRA, 2008, p. 86).

Seguindo essa ótica de entendimento, nota-se com maior facilidade por que o aludido vocábulo era marcado graficamente com o hífen diante de substantivos antes da vigência do Acordo Ortográfico de 1990. Em linhas gerais, a marcação gráfica ocorria porque o vocábulo "não", tradicionalmente advérbio, transpunha-se a prefixo, deixando de ser um circunstancializador para participar no processo de formação de uma nova palavra, conservando uma relação de sentido com o radical a partir do qual ocorreu a derivação (prefixal, para fins deste trabalho).

Sobre isso, cabe ressaltar que o trajeto de transposição do "não", de advérbio a prefixo, insere-se no processo de mudança linguística que busca a acomodação do item lexical ao significado que se quer atribuir ao vocábulo a que se acopla o prefixo. Ao discorrer sobre o processo de gramaticalização em Hopper e Traugott, 
Campos (2009) entende que tais autores o consideram como

a parte do estudo da mudança linguística preocupado em analisar como itens lexicais e construções, em determinados contextos linguísticos, passam a desempenhar funções gramaticais e/ou como itens gramaticais passam a desenvolver novas funções mais gramaticais ainda" (Idem, p. 249).

Partindo de tal concepção, entende-se que a função prefixal alçada pelo advérbio "não", assim tradicionalmente considerado, é resultado de um processo de gramaticalização a partir do qual tal vocábulo, investido em uma nova função, não apresenta, de fato, "a função de relacionar a palavra ao restante da frase (não indicam marcas flexionais) [...], o que torna a prefixação um processo de criação de novos vocábulos semeIhante à composição" (PEREIRA, 2008. p. 86).

\section{A QUESTÃO SEMÂNTICA}

Considerando que a Semântica "é o estudo da significação das palavras e das suas mudanças de significação através dos tempos ou em determinada época" (SACCONI, 2001, p. 485), há de se considerar, a princípio, que as palavras sofrem influência direta do dinamismo da língua e das necessidades comunicativas, verbal ou escrita, no que diz respeito à sua significação. Isso ocorre porque de fato "a língua é uma atividade social, um trabalho coletivo, empreendido por todos os seus falantes, cada vez que eles se põem a interagir por meio da fala ou da escrita" (BAGNO, $2007 a$, p. 36), funcionando como um verdadeiro processo que se reconstrói e se desfaz conforme a necessidade dos falantes.

Menezes e Pante (2003), compartilhando dessa visão, explicam que

a língua de um povo é dinâmica, transforma-se através do tempo, de forma que algumas palavras desaparecem; outras permanecem, adquirindo novos sentidos ou perdendo sentidos que já tinham; palavras novas surgem, conforme as necessidades comunicativas da sociedade (Idem, p. 51).

Apesar de convencionada e normatizada pela gramática, a língua é um instrumento de comunicação nunca concluído. Na verdade, "a variação e a mudança linguísticas é que são o 'estado natural' das línguas" (BAGNO, 2007a, p. 37). Essa natureza mutável dos empregos linguísticos e da significação das palavras corrobora que a língua é viva, sugerindo uma definição mais completa da Semântica como área de estudo. Nesse sentido, vale ressaltar que a Semântica se preocupa com

mecanismos e operações relativos ao sentido, através do funcionamento das línguas naturais [...], 'tentando' explicitar os elos que existem entre os comportamentos discursivos num dado envolvimento, constantemente renovado, e as representações mentais que parecem ser partilhadas pelos usuários das línguas naturais (Pottier apud HENRIQUES, 2009, p. 121).

A respeito do valor semântico do prefixo "não", os autores consultados não divergem quanto ao valor negativo que impregna o vocábulo, mas também não dedicam espaço significativo a fim de tratar de tal assunto, limitando-se a notas e observações acerca do emprego do hífen e da equivalência a outros prefixos também de valor negativo. Desta feita, é importante analisar o aspecto semântico dos demais prefixos de valor negativo.

Vários elementos prefixais com sentido de negação podem ser identificados nos compêndios gramaticais, tais como a-, anti-, contra-, des-, in- e sem-, porém, devido ao objetivo deste trabalho e por estarem cristalizados em relação ao uso na Língua Portuguesa, a atenção analítica recairá apenas sobre os prefixos a-, des- e in-

Compilando as informações contidas em Bechara (2009), Cegalla (2000), Cunha e Cintra (2012) e Sacconi (2001), notase que o prefixo a- é considerado de origem grega, denotando as noções de:

- privação, negação, insuficiência, carência, contradição, como em afônico, anemia, anônimo, anoxia, amoral (BECHARA, 2009, p. 368), assumindo a forma an- quando anteposto a vogal;

- negação, carência: ateu, abulia, afônico, acéfalo, anemia, anonimato, anarquia, analgésico, anestesia (CEGALLA, 2000, p. 112), podendo assumir a forma an-, mantendo-se o sentido;

- privação, negação, como em anarquia, ateu (CUNHA e CINTRA, 2012, p. 101), tanto para a forma an- quanto para a forma a-;

- negação, privação, falta: anômalo (que não é normal), analfabeto (sem alfabeto), átono (sem tom), acéfalo (sem cabeça), ateu (sem Deus), anarquia (sem governo), anônimo (sem nome), anêmico (sem sangue), anidro (sem água), apatia (falta de sentimento), afônico (sem som), amorfo (sem forma), entre outros (SACCONI, 2001, p. 100), observando que "usa-se a- antes de consoante e an- antes de vogal" (Idem, ibid).

Quanto ao prefixo des-, todos os autores supracitados consideram-no de origem latina, registrando a forma dis- como alternativa àqueloutra. Cunha e Cintra (2012) mencionam, outrossim, a forma di- (dir-). Já Sacconi (2001) assinala a forma de- como variante de des- e a foma di-como variante de dis-. 
- de(s), di(s) (negação, ação contrária, cessação de um ato ou estado, ablação, intensidade): desventura, discordância, difícil (dis + fácil), desinfeliz, desfear (= fazer muito feio), desmudar (= mudar muito) (BECHARA, 2009, p. 366);

- des, dis - negação, ação contrária, separação, afastamento: desarmonia, desonesto, descascar, desfazer, deslembrar, desterrar, dissentir, dissociar (CEGALLA, 2000, p. 110);

- des- (separação, ação contrária): desviar, desfazer (CUNHA e CINTRA, 2012, p. 99); dis-, di(dir-) (separação, movimento para diversos lados, negação): dissidente, distender, dilacerar, dirimir (Idem, ibid.);

- des- (negação, ação contrária, aumento, intensidade, destruição, separação): desleal, desarrumar, desinquieto, desmoronar e descascar. Variante: de-: decair, demorar, dejúrio (SACCONI, 2011, p. 97).

Em conjunto ao prefixo latino in- (assim considerado pelos autores consultados), encontram-se as formas im- e $i$-, ambas assumidas pelo prefixo in- diante de situações léxicas diversas, sendo que "o prefixo in- reduz-se a i- antes de l, $m, n$ e r: ilegivel, imóvel, inocente, irresponsável. Antes de b e p assume a forma im-: imberbe, improdutivo" (CEGALLA, 2000, p. 110). Quanto aos valores semânticos, há os seguintes registros:

- in-, im-, i- (sentido contrário, negação, privação): impenitente, incorrigivel, ilegal, ignorância (BECHARA, 2009, p. 367);

- in, im, i - negação, carência: indelével, infelicidade, impune, imberbe, ilegivel, ilegal, irreal, irracional, irredutível, irresoluto (CEGALLA, 2000, p. 110);

- in- (im-), i- (ir-) (negação, privação): inativo, impermeável, ilegal, irrestrito (CUNHA e CINTRA, 2012, p. 99).

Relativamente ao último prefixo negativo analisado, Cunha e Cintra (2012) frisam que

as alterações sofridas pelos prefixos são provocadas quase sempre pelo fenômeno chamado ASSIMILAÇÃO, que consiste em absorver um as características de outro que the está contíguo. Como, em geral, a ASSIMILAÇÃO identifica os dois fonemas, é comum o desaparecimento de um deles: in-legal > il-legal > ilegal. Advirta-se, em tempo, que a ASSIMILAÇÃO é um fato fonético, e não deve ser confundida com as acomodações que, na escrita, sofrem certos prefixos por exigência do nosso sistema ortográfico. Assim, in-fiel, mas im-produtivo; i-migrar, mas ir-romper; etc. São essas as variantes puramente gráficas que colocamos entre parênteses (CUNHA e CINTRA, 2012, p. 100).

Partindo dos valores semânticos e dos inúmeros exemplos apresentados pelos gramáticos em suas respectivas obras, pode-se adentrar no aspecto da atipicidade que incide sobre o vocábulo "não", relativamente à queda do hífen em compostos por ele iniciados, alteração trazida pelo Acordo Ortográfico de 1990. Contudo, é necessário salientar que a questão semântica é mais complexa que a ortográfica, merecendo, portanto, maior aprofundamento analítico e a adoção de outras formas de pesquisa que transbordem o que pretende este artigo.

\section{OS ASPECTOS DA ATIPICIDADE ESTRUTURAL}

De acordo com as novas regras ortográficas, não mais se emprega o hífen diante de compostos iniciados pelo vocábulo "não" em função de prefixo. Isso significa que, antecedendo a um substantivo ou a um adjetivo, tal afixo (prefixo) deixou de receber a marcação gráfica que claramente o deslocava para a função prefixal.

Ante a queda do traço de união diante desse tipo de nome composto, emerge o primeiro impacto de atipicidade estrutural: a palavra, de base prefixal, fica solta, adquirindo maior independência em relação ao nome ao qual se ligava no momento da constituição do processo antonímico, que diz respeito "ao fato de haver palavras que entre si estabelecem uma oposição contraditória (vida; morte), contrária (chegar; partir) ou correlativa (irmão; irmã)" (BECHARA, 2006, p. 551), inclusive relativamente ao uso de prefixo negativo antes das palavras que sofrerão o procedimento contrastivo.

Desse modo, palavras como não cumprimento (anteriormente grafada com hífen) e descumprimento, a partir do Novo Acordo Ortográfico, são, na verdade, um radical ao qual se conecta um prefixo de valor negativo, capaz de imprimir ao vocábulo um novo valor semântico. 0 que ocorre é que 0 nome ao qual é anteposto o prefixo recebe uma carga extensiva de significação, restando ao vocábulo derivado um novo significado, mais ampliado que o anterior. Contudo, nesta palavra (descumprimento), diferentemente daquela (não cumprimento), o prefixo está acoplado ao substantivo, importando, por conseguinte, a inexistência de independência estrutural. Logo, embora ambos os prefixos citados tenham valor negativo próximo, mas não idêntico, suas estruturas são distintamente dispostas diante do vocábulo a que se adjunge.

Com efeito, nos exemplos que serviram de base às 
explicações do subtítulo anterior, fica evidente que os prefixos a-, in- e des- participam no processo de formação das palavras pelo acoplamento ao nome subsequente, sendo desnecessário o emprego do hífen. Em contrapartida, a prefixação promovida pelo uso do "não" deslocado da função adverbial era marcada pelo uso dessa notação léxica. Assim, de modo atípico, a expressão não cumprimento é composta de um prefixo solto e independente, sem a marcação gráfica que caracteriza o deslocamento de função, mais um substantivo que recebeu a carga do processo antonímico.

Em razão do grau de independência adquirido pelo prefixo "não" nesse processo de gramaticalização, assumindo não apenas um sentido peculiar, já que também de valor semântico negativo, tal como o "não" em função de advérbio, mas também um acentuado grau de independência, poder-se-ia classificá-lo como um dos pseudoprefixos, os quais se caracterizam

a) por apresentarem um acentuado grau de independência; b) por possuírem 'uma significação mais ou menos delimitada e presente à consciência dos falantes, de tal modo que o significado do todo a que pertencem se aproxima de um conceito complexo, e portanto de um sintagma'; c) por terem, de um modo geral, menor rendimento do que os prefixos propriamente ditos (CUNHA e CINTRA, 2012, p. 128).

A despeito da assertiva dos autores, ao que parece, o "não" prefixal, mesmo não sendo um prefixo propriamente dito, apresenta maior rendimento do que os prefixos in- e des- ou de-, considerados "os prefixos negativos mais comuns" (BECHARA, 2009 , p. 367), bem como relativamente ao prefixo a-, visto que aproximam pela oposição de sentido o vocábulo a que se adjunge à antonímia. Assim, o prefixo em questão se aproximaria das duas primeiras proposições dos gramáticos, mas se afastaria da terceira.

Nessa linha de raciocínio, seria plausível o entendimento de que o emprego do "não" prefixal passa a ser, com o advento da Reforma Ortográfica, uma particularidade linguística no que diz respeito ao seu processo de gramaticalização que, de certa forma, foi impulsionado pelo Acordo. No entanto, não se intenciona levantar hipóteses de variação semântica unicamente com base em uma reforma de cunho ortográfico, tendo em vista que a língua, por óbvio, reveste-se de dinamicidade muito maior do que a ortografia, sujeitando-se a mudanças independentemente desta.

À guisa de exemplo, o vocábulo não-homem, grafado com hífen propositadamente diante de um substantivo, não remete o leitor diretamente à compreensão do antônimo mulher, podendo significar também aquele que não é humano, graças à interação do prefixo negativo com o substantivo que o sucede. Isso significa que o item lexical em questão é mais que um mero prefixo que pressupõe a antonímia, podendo ampliar significações que, de outro modo, seriam estanques.
Esse deslocamento de significado pode ser propositado ou não a depender da vontade do falante ou escritor e do significado que pretendem com o emprego das palavras, já que eles são os "donos" de seu idioma.

Sobre isso, Cegalla (2000, p. 80) observa que "em formações como não-intervenção, não-existência, não-agressão, nãofumante, não-alinhado, etc., que o uso vai consagrando, considera-se 'não' prefixo negativo, daí a presença do hífen[...]" , já registrando o emprego do sinal diacrítico antecedendo tanto substantivos quanto adjetivos. Isso pode ser explicado a partir da visão que permite ao escritor que maneja a língua adotar o "não" em função prefixal, conferindo uma ampliação de significado ao nome (adjetivo ou substantivo, para esse efeito), ou adotá-lo como simples advérbio, caso se apresente anteposto a um adjetivo.

Nessa perspectiva, é válido ressaltar que a dinamicidade da força significativa do item lexical em análise não se encerra na relação com os substantivos, atingindo, outrossim, os adjetivos e os particípios. A fim de corroborar tal afirmação, Campos (2009) explica que

em virtude do caráter híbrido do particípio, qual seja 'verbal' e 'nominal', podemos observar que se enfraquecem os limites entre a forma livre do advérbio e a forma presa do prefixo, elementos representados pelo item léxico-gramatical não, dando origem a um contexto de intersecção entre as duas categorias propostas (idem, p. 259).

Em acréscimo ao primeiro aspecto de atipicidade, relacionado à independência prefixal pela ausência da marcação clara de deslocamento de função, desponta um segundo aspecto relacionado ao processo antonímico, posto que o "não" prefixal contribui para formação de um antônimo mais perfeito, se comparado à produtividade dos demais prefixos de valor negativos analisados.

Considerando parte desse entendimento, Sacconi (2001) explica que

quando o "não" funciona como autêntico prefixo, equivale a in-, liga-se ao substantivo mediante hífen (o não-conformismo, a não-intervenção, o não-pagamento, o não-comparecimento, etc.); quando, porém, o "não" antecede adjetivo, não há hífen (livro não descartável, bens de consumo não duráveis, infinitivo não flexionado, menor não infrator, problemas não resolvidos, governo não comunista, etc.) (Idem, p.59).

Nessa citação, observa-se que o professor desconsidera a possibilidade do emprego do hífen diante de adjetivos, inclusive particípios, prezando em seu compêndio gramatical pela manutenção do sinal gráfico apenas diante de substantivos, como se pretendesse uma generalização do valor semântico contido no prefixo "não". O que ocorre, todavia, é que, se considerados, por exemplo, 
os aspectos de expressividade sugestionados pelo próprio composto, a ausência do hífen desconstrói as nuances da estrutura não+adjetivo, quando esta é submetida a uma análise contrastiva.

Logo, em não-humano (grafado com hífen antes de adjetivo propositadamente), tem-se um valor semântico diferenciado se em comparação com desumano, visto que o primeiro exemplo, devido à intencionalidade do escritor, fará alusão a um ser que não é humano, que pertence a outro planeta talvez. Diferentemente, em desumano, pressupõe-se a característica de quem agiu com ausência de humanidade, ou seja, distante dos critérios que aproximam o homem à humanidade que nele deveria se encerrar. Isso significa, portanto, que, mesmo diante de adjetivos, há utilidade intencional do escritor quando utiliza o hífen e essa intencionalidade, em contrapartida ao que apregoa o Acordo, pertence ao indivíduo. Essa assertiva pode ilustrar a afirmação de Bagno (2007b, p. 9) de que "a gramática não é a língua", posto que, caso seguida à risca uma norma convencionalmente adotada, o indivíduo perde a "propriedade" de seu texto, deixando de ser "dono" do que pretende significar.

Nesse foco, Campos (2009) observa que as expressões não concluída e não submissa, em virtude da aposição do "não" prefixal, sugerem uma possibilidade dinâmica, significando, nesse caso, que ambas as expressões remetem a uma situação de transitoriedade. Em contraposição, se analisados os vocábulos inconclusa e insubmissa, resvala dos prefixos uma ideia de condição permanente.

Assim sendo, conquanto a supressão do hífen nos compostos facilite o emprego desse sinal e o manejo da língua, sucumbem algumas possibilidades de que poderia fazer uso o escritor a fim de refletir no texto marcas mais precisas de entendimento ou de vontade, não pela simples inaplicabilidade de um sinal gráfico, mas pela força explicativa que se desfaz juntamente com ele. Logo, esse recurso ortográfico estaria à disposição apenas daqueles que possuem a famosa "licença poética".

\section{CONSIDERAÇÕES FINAIS}

Apesar de se tratar de uma reforma de cunho ortográfico, o Acordo de 1990 ultrapassa as barreiras da grafia e da morfologia e atinge, de certo modo, a semântica que envolve o uso e a aplicação do "não" em função prefixal, visto que a atipicidade que sobrevém à estrutura do nome derivado que dele faz uso transborda para o viés do significado.

A rigor, a palavra "não" é morfologicamente classificada como advérbio de negação, transpondo-se a prefixo com valor negativo em razão não apenas do dinamismo linguístico que circunda o manejo da língua, mas também da necessidade de formação de palavras que respondam às particularidades da escrita em conjunção com os anseios daquele que dela se utiliza.
Desse modo, mesmo com a queda do hífen nos nomes compostos, considerados aqui derivados quando antecedidos do prefixo "não", a língua dispõe de diversos recursos de auxílio à aproximação de significados, haja vista a existência de outros prefixos negativos, cada qual peculiar em relação à origem e aos usos. Isso significa que o "não" em função prefixal agrega valores à língua, subsumindo sentidos em vez de destituí-los dos vocábulos.

Nota-se, no entanto, que da ausência da marcação gráfica na estrutura não+nome (substantivo ou adjetivo) insurge uma atipicidade estrutural ratificada pela independência adquirida pelo prefixo "não", que antes se mantinha preso ou, em outras palavras, unido pelo hífen, ao nome com o qual se relacionava a fim de formar a nova palavra. Com isso, poder-se-ia considerar tal prefixo como um pseudoprefixo, na verdade, tirante a questão da produtividade lexical, uma vez que é mais simples manejar o "não" como prefixo do que aqueles já cristalizados, mas considerados formas presas, tais como a-, des- e in-. E, de fato, é esta a conclusão a que se chega com base nas análises e nos conceitos retroexpostos: o "não", na verdade, tende a se firmar como pseudoprefixo, já que seu emprego anteriormente prefixal perdeu características que justificavam tal classificação, adquirindo novas que, aliadas à natureza primeira de advérbio, resultam em maior independência estrutural.

Ademais, o próprio emprego de tal advérbio transposto a pseudoprefixo interfere no processo semântico de antonímia, bastando negar o substantivo ou adjetivo para que se obtenha um nome negativo. Contudo, essa negação nem sempre desemboca em um antônimo perfeito, produzindo, por vezes, palavras ampliadas de sentido que se aproximam de um efeito contrastivo, o que não se trata da isenção de um novo aspecto de atipicidade, mas de um acréscimo.

Por fim, a despeito da atipicidade estrutural que impele uma suposta atipicidade semântica, o uso do prefixo "não" diante de nomes, mas desacompanhado do hífen, não suscita questões suficientemente significativas para a inviabilização do manejo da língua, afora, por óbvio, os preceitos morfológicos e classificatórios que, a propósito do trabalho, refletem um verdadeiro processo de gramaticalização em que o "não" transpõe-se de prefixo a pseudoprefixo. Isso decerto corrobora que a dinamicidade e a mutabilidade da língua atingem inclusive a gramática normativa, com contornos que podem ser desenhados pela intencionalidade do indivíduo que se vale da "propriedade" de seu idioma. 


\section{REFERÊNCIAS}

ANTUNES, I. Lutar com as palavras: coesão e coerência. $1^{\text {a }}$ Edição. São Paulo: Parábola Editorial, 2005.

BAGNO, M. Nada na língua é por acaso: por uma pedagogia da variação linguística. $1^{\text {a }}$ Edição. São Paulo: Parábola Editorial, 2007a.

Preconceito linguístico: o que é, como se faz. $49^{a}$ edição. São Paulo; Edições Loyola, 2007b.

BORTONI-RICARDO, S. M. Educação em língua materna: a sociolinguística na sala de aula. São Paulo: Parábola Editorial, 2004.

BECHARA, E. Gramática Escolar da Língua Portuguesa.

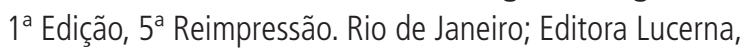
2006

. Moderna Gramática da Língua Portuguesa

$37^{a}$ Edição. Rio de Janeiro; Editora Nova Fronteira, 2009.

BRASIL, Decreto $n^{\circ}$ 6.583, de 29 de setembro de 2008 . Promulga o Acordo Ortográfico da Língua Portuguesa, assinado em Lisboa, em 16 de dezembro de 1990.

CALVET, L. J. Sociolinguística: uma introdução crítica. $2^{\text {a }}$ Edição. São Paulo: Parábola, 2002.

CAMPOS, L. O desenvolvimento do prefixo não. In: OLIVEIRA, K.; CUNHA e SOUZA, H, F.; SOLEDADE, J (orgs.). Do português arcaico ao português brasileiro: outras histórias. Salvador; UDUFBA, 2009. Disponível em http://books.scielo. org/id/3fz/pdf/oliveira-9788523208714-13.pdf. Acesso em 25/08/2013.

CEGALLA, D. P. Novíssima Gramática da Língua Portuguesa. 43a edição. São Paulo; Companhia Editora Nacional, 2000.

CIPRO NETO, P.; INFANTE, U. Gramática da Língua Portuguesa. $1^{a}$ Edição. São Paulo; Scipione, 1998.

CUNHA, C.; CINTRA, L. Nova Gramática do Português Contemporâneo. $5^{a}$ Edição. Rio de Janeiro; Lexicon Editora Digital, 2012.

FERREIRA, A. B. H. Dicionário Prático da Língua Portuguesa. Rio de Janeiro; Editora Nova Fronteira, 1997.
HANKS, W. F. Língua como prática social: das relações entre língua, cultura e sociedade a partir de Bourdieu e Bakhtin. $1^{\text {a }}$ Edição. São Paulo: Cortez, 2008.

HENRIQUES, C. C. Língua Portuguesa: semântica e estilística. Curitiba: IESDE Brasil, 2009.

KOCH, I. G. V. A inter-ação pela linguagem. $11^{\text {a }}$ Edição. São Paulo: Contexto, 2012.

LUFT, C. P et al. Dicionário Brasileiro Globo. 53ª Edição. São Paulo; Globo, 2000.

MENEZES, A. C.; PANTE, M. R. O prefixo "não": polissemia e produtividade no processo de formação de palavras. Acta Scientiarum: human and social sciences, Maringá, v. 25, nº 1, p. 051-057, 2003

NICOLA, J.; INFANTE, U. Gramática Contemporânea da Língua Portuguesa. São Paulo; Editora Scipione, 1997.

PEREIRA, P. A. Para uma distinção entre radical e prefixo: será não-composto um composto ou um derivado? Estudos Lingüísticos, São Paulo, n 37, p. 83-92, jan./abr. 2008.

PERINI, M. A. Para uma nova gramática do português. São Paulo: Ática, 1985.

POSSENTI, S. Por que (não) ensinar gramática na escola. Campinas: Associação de Leitura do Brasil (ALB)/Mercado de Letras, 1996.

SACCONI, L. A. Nossa Gramática - Teoria e Prática. 27ª edição. São Paulo; Atual Editora, 2001.

SCHERRE, Ma M. Doa-se lindos filhotes de poodle: variação linguística, mídia e preconceito. São Paulo: Parábola Editorial, 2005.

TAKAZAKI, H. H. Língua Portuguesa. São Paulo: IBEP, 2004.

WEEDWOOD, B. História concisa da Lingüística. $1^{\text {a }}$ Ed. São Paulo: Parábola Editorial, 2002. 